\title{
REVIVING CONTEMPORARY URBAN DESIGN: CASE OF HISTORIC CITY SULTANPUR LODHI, PUNJAB, INDIA
}

\author{
Vikas Chand SHARMA* \\ Chandigarh University, Gharuan, Mohali
}

Received 02 September 2018; accepted 11 November 2018

\begin{abstract}
Cities have a long and varied urban history, but cities in developing countries have had a relatively brief experience with the modern city. What are the current urban ideas of Indian Cities? How does this ideology affect modern city design? And how is city design related to traditional City design of related province? These questions have led the author to undertake this study. Urban planning and Designing into towns is the beginning of the difficulties of cities' futures. Whether the main problem is the way of designing and planning or the policy of increasing the population, what New Towns today mainly suffer is the lack of identity and the differentiation between other cities.

"For Indian cities, need of multiple models for well-functioning cities with some common ingredients, including a commitment to equality of opportunity, smart designs for upcoming cities, improved housing facilities, smart designs for upcoming cities and a drive to improve the quality of life for habitants has been felt in the twenty first century."

Sultanpur Lodhi with its legacy to have historic palaces, vital landscape, relics from various architectural styles offers a possibility to explore city module for reviving of historical cities. It was found that 81 percent of the urban population in city lived in overcrowded and substandard houses (Office of Punjab urban planning and development authority, 2017). Therefore this is one amongst the top three most densely populated cities in Punjab, India. Its culture combines Hindu, Buddhist, Islamic, Sikh and British influences. As the economy of this city is based on Agro based industries like Rice Sheller and other small scale industries and subsequent housing demand, there is need to protect vibrant culture and impressions. A fine tunings between available local resources and Contemporary urban design practice need to be explored. The study of Sultanpur Lodhi attempts to give reviving a historical and coherent summary of fragmented information about Punjab's urban design practice.
\end{abstract}

Keywords: urban identity, historic town and contemporary urban design, culture.

\section{Introduction}

Culture is driving factor for evolution of Historical Cities in developing countries. In India, Urban design of Varanasi, Madurai and Delhi are having imprints of the various dynasties or religion at their forefront. Sultanpur Lodhi is one of the ancient cities of India, though it has been established in the first century of the current era. It has witnessed the difficulties of politics, religion, literature, trade, and commerce. It carries a lot of memories from its proud past. It is situated on the left bank of the rivulet, called "Kali Bein" about 6 miles north of the intersection of Beas and Sutlej Rivers, district Kapurthala, Punjab, India (Figure 1).

Apart from walled city of Jaipur and Amritsar, Sultanpur Lodhi has a clear defined visual boundary followed by National highway at southern side and perennial rivulet at northern side of the city. Identified boundary of this city limitized the use of agricultural land for new construction and helped to retain potential use of existing resources for city dwellers.

\section{Historical perspective Sultanpur Lodhi}

From the first century to the sixth century, it was one of the major centers of meditation and knowledge for Buddhism (Figure 2). In that period, the town of Sultanpur Lodhi was known by the name of "Sarwmanpur". Trade coins, statues, and related objects were found during the archeological excavations of Sultanpur Lodhi.

In the eighth century, the town became a great empire of Hinduism and Buddhism. It was founded by Sultan

${ }^{*}$ Corresponding author. E-mail: ar.vikassharma@gmail.com 


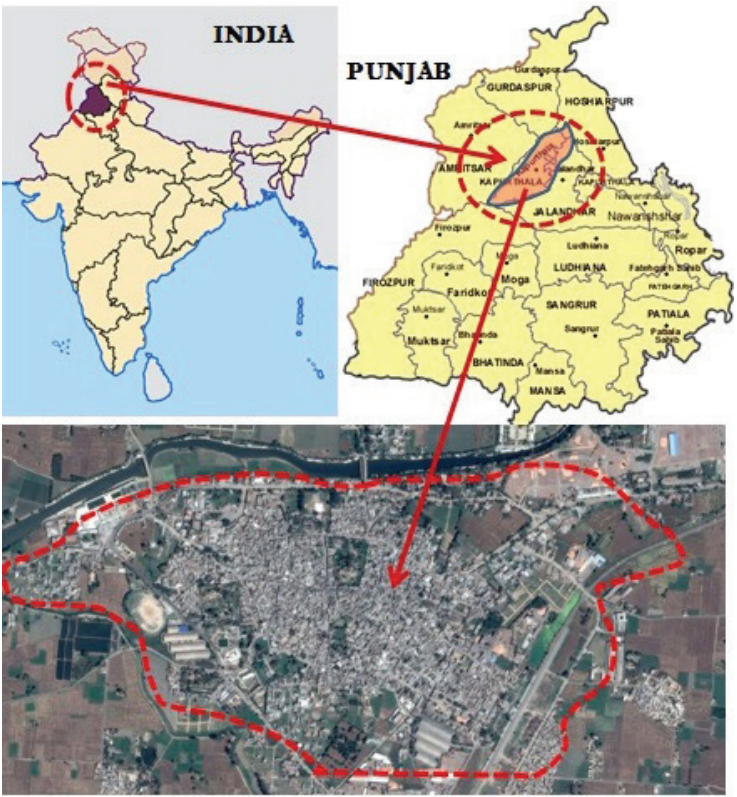

Figure 1. Geographical location of Sultanpur Lodhi (source: Google map)

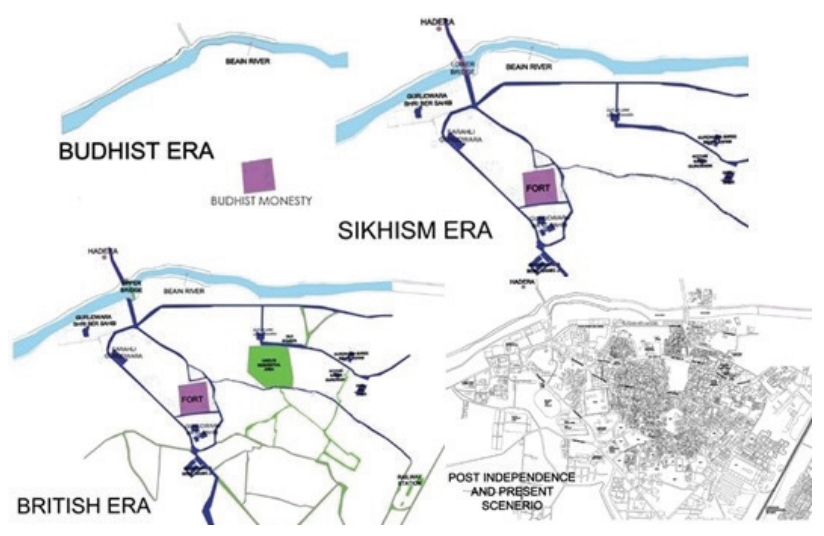

Figure 2. Evolution of city Sultanpur Lodhi (source: by author)
Khan Lodhi a General (Faujdar) of Mohamad Gaznavi in the 11th Century A. D. and was an earlier main town of Doaba Region. During the time of Sikander Lodhi, the famous Sultan of Delhi assigned the construction of Sultanpur to Nawab Daulat Khan of Lahore. He gave a very beautiful landscape to the environment of this town and turned it into a Nakhilstan (Green Patch) and play-hunt (Sikargarh). The city had many royal gardens and farms. One of these is "Hadira", used as place of rest and for entertainment for the royal family.

Sultanpur Lodhi, in those days, was not only famous for the special qualities of the land and surrounding, its trade but also for its educational institutions. Many of the Islamic schools of education known as MADRASA were there (Ali, 2015). This new town of Sultanpur Lodhi was also the centre point of the old trade route between Delhi and Lahore. At that time it was one of the major trade centers of North India. It consisted of 30 major markets and about 5000 shops. At that time, the town was spread over an area of 8 square miles. The Kali Bein at that time runs through the centre of the town. These features at that time were more than enough to make it a big town. In north India, the main trade hub of Mughals was Sultanpur Lodhi and later on, it was shifted to Kapurthala. The city of Sultanpur Lodhi had retained some point of interest or landmarks till today.

At the end of the 14th century, The Governor of the Lahore Daulat Khan Lodhi ruled it. Sultanpur Lodhi before the start of Sikhism was also called Peeranpuri (Town of Monks). Many of the tombs (Makabras) of these monks are still present in the town. Today Sultanpur Lodhi has several Gurudwaras Commemorating events connected with the life of Guru Nanak Dev Ji.

The other places of historic interest are Sarai of Sher Shah Suri's period in which presently the Police station, Tehsil, and Court of Sub-Judge are located, Hadira a dilapidated building situated across Bein, was used as a place of recreation during Mughal Period.
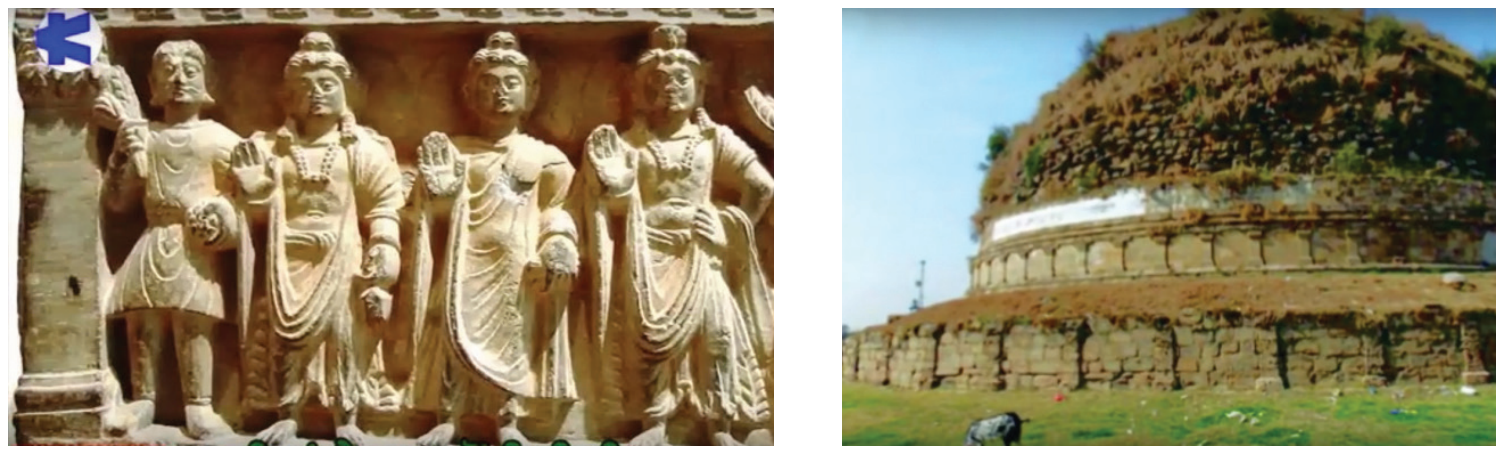

Figure 3. Relics from Buddhism culture: sculptures and tomb (source: Google image) 

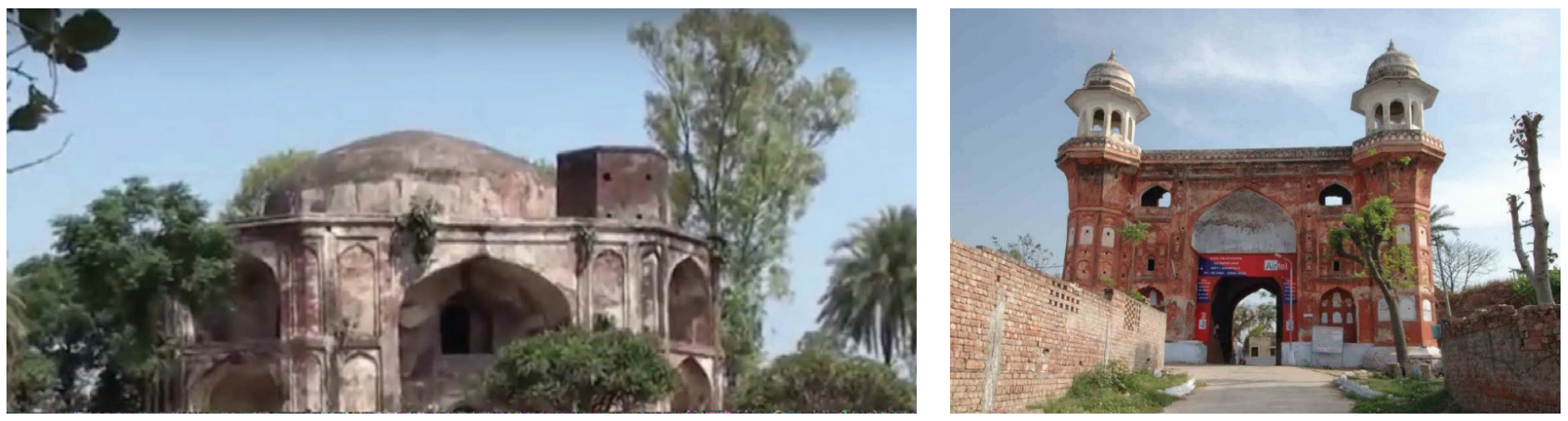

Figure 4. Relics from Mughal culture: Tomb and entrance gateway at Sultanpur Lodhi (source: Google image)
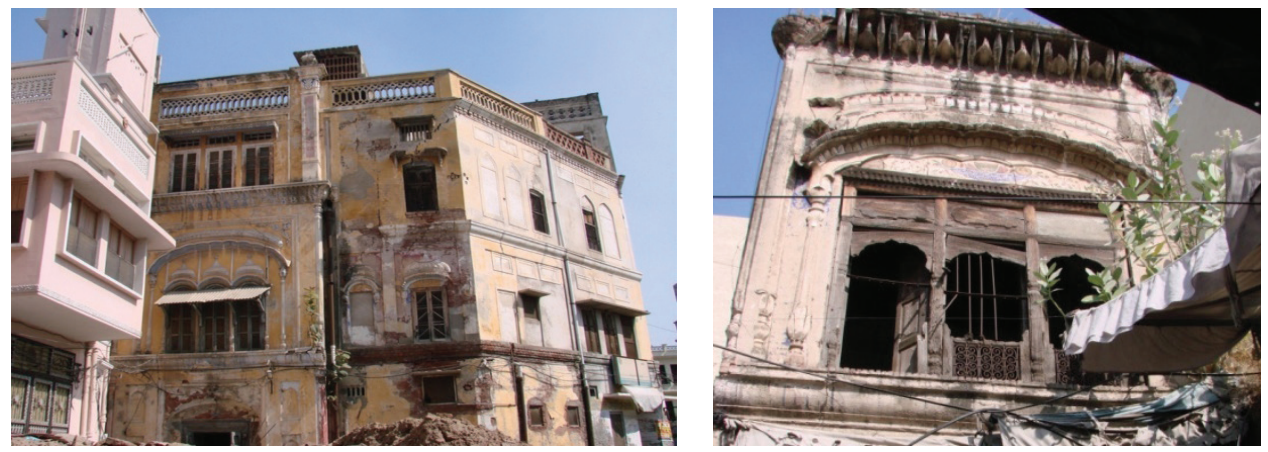

Figure 5. Relics from Sikhism culture: Bebe Nanki House (Haveli) (source: by author)
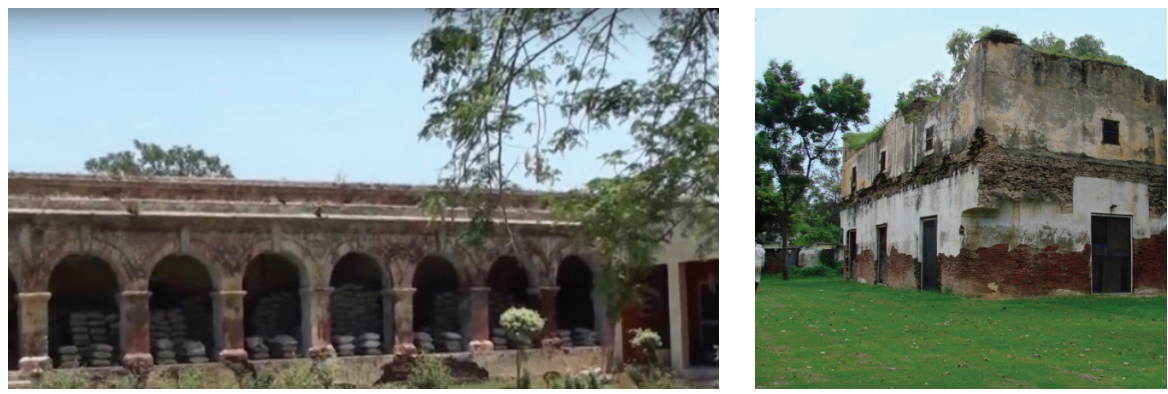

Figure 6. Relics from British Era: post independence (source: by author)

The city has witnessed erection of public buildings in post independence period. These buildings usually have colonnade verandah, courtyards and big open spaces of defense character (Figure 6). Awareness of history of a place increases people attachment to the place and the historical sites in the precinct. Hayden (1995) talked about "Urban Reminders". This can be structures, architecture styles, graffiti, ruins, etc. This help in passing on past information, arousing inquisitiveness and motivated to discover the intricacies of place. In this case, the points of pauses, where rituals are carried out can be used as 'mnemonic aids' to collective memory.

\section{Methodology}

Reviving of historical cities in urban design may not only refer to the concrete transformations in built forms. It carries the revival and preservation of design approach to future growth. The city Sultanpur Lodhi witnessed the numerous kingdoms and culture thereof. Keeping in view the historical background and future growth projections of the city, Contemporary principles of urban design were analyzed. Landuse, ecology, built forms, heritage, tourism and transportation issues are considered for study. Basic planning methodology while conducting the study is as follows:

1) Primary data collection through photographic and field surveys with separate questionnaires for city dwellers and visitors.

2) Secondary data collection through a thorough study of the relevant literature.

3) Identification and analysis of major urban design principles.

4) Framing recommendation and relevant proposals accordingly. 


\section{Urban identity}

Then city growth has been directed towards vast parcels of vacant agricultural land towards the south and the main source of trade became agriculture. At present it has eight Gurudwaras as eccentric pivotal points scattered within city boundaries. The organically developed city layout is growing parallel to existing perennial water source which forms a perpendicular axis along the development (Figure 8). Diverse quality of organic cities in developing countries a fusion of existing grains can be traced here (Figure 7).

Grain of Sultanpur Lodhi is showing gradual evolution of grains from organic to structure. Linear, Radial, Curvilinear and grid approach can be traced here.

The concept propounds that Sultanpur Lodhi's urban identity includes the characteristics and values of Pun$\mathrm{jab}$ architecture and urbanism before the arrival of $\mathrm{Mu}$ ghals to Sultanpur Lodhi. Sultanpur Lodhi as developed a trade centre earlier has eight major Gurudwaras which connects each other on a visual axis. their connecting visual axis (Figure 10), Mandir Sing Bhawani, Mandir BharaMal, Mandir Ahli Wala Shivala, Mandir Mata Asha Rani, Mandir Ram Rameshwaram, Madir Choura Khuh etc., Chitti Masjid, Peer Gabgazi, Panj Peer, Hadira, Quila Sarai (Now housing, Local Police Station), Kali Bein (A rivulet of Beas river). These are prominent urban tissues in the city to acknowledge rich cultural heritage site. Another important element, namely the bazaar is not planned as such commercial areas are overreaching to residential zones (Figure 8).

Landuse map showing Residential, Commercial, Public and Semipublic, Recreational and institutional zoning. Intervention of commercial patches can be traced in reference with the city expansion.

Symbol of urban identity (at least from the physical spatial dimensions point of view) is represented by the five key elements of the urban structure, which is formed earlier from the first $\mathrm{AD}$ to proceeding years in harmony with the climatic, economic, and social conditions, and

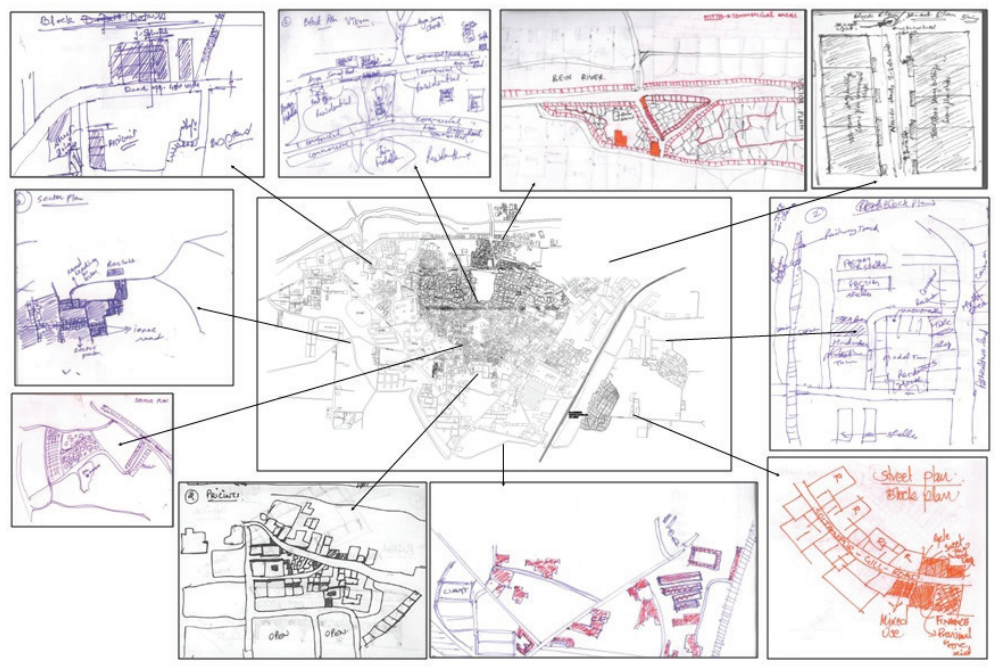

Figure 7. Block detail: Grain of the city Sultanpur Lodhi (source: by author)

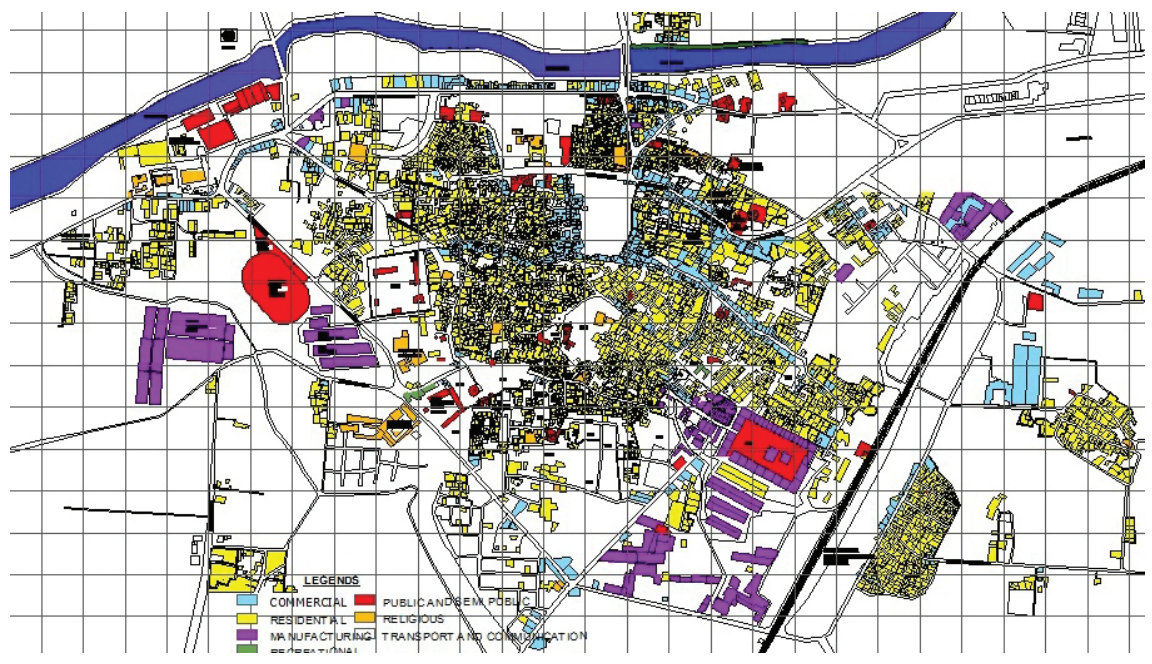

Figure 8. Landuse map Sultanpur Lodhi (source: by author) 
along with the advancements made by the preaching of those religious thinking's as Buddhism, Mughal and Sikhs.

The identity, physical and spatial characteristics of the Sultanpur Lodhi city were highly correlated and interdependent as they were combined with the various influences while the replacement of traditional elements with new ones, some building as Quila Sarai is being used as housing and police station. Gurudwaras led to the formation of identity with a particular physical space with their associated elements as gathering grounds (Plaza's), Gurudwara Ber Sahib located on the bank of the rivulet Kali Bein and their surrounding neighborhoods, and other spaces such as grain market. During festivals as Holla-Mohalla, Diwali and religious ceremonies group parade has been performed and existing open spaces have ample space for these types of activities. These spaces also serve as additional parking spaces during these fests.

Residential layouts are consisting centralized or front courtyard as a typical vernacular element of Punjab architecture. Houses which belong to Jain families are having big entrance gateway followed by a lobby or verandah at front. People response to existing planning module was found satisfactory as it serves their needs (Tersteeg \& Albeda, 2015). City dwellers are having strong family relations and usually, joint families are living together. Open spaces of Courtyards and Lobbies are extensively used during non-working hours and at gathering time. These open spaces are also being used for in-house parking and few commercial activities. Duplex houses with a balcony towards street facilitate street view during ceremonial activities (Figure 9).

Linear shape Commercial layouts are being used for shops and offices. Single storeyed commercial buildings have the provision of densification further. The well maintained old buildings are being used for commercial purpose. It provokes a good example of adaptive reuse build- ings here. A range of Jain, Sikh, Mughal and colonial architecture is traced. Apart from streets of residential areas commercial streets are wide enough and being occupied for goods display, banner display, and temporary parking. It conflicts the users perspective on the use of commercial streets. A few shops unit built during the post-independence period has the provision of parking lots.

Institutional layouts are spread out throughout the city (Figure 12). Evolution of these places is gradual outcome of the religion-based culture. Gurdwara's, Mosque and Temples are located on a terminated end of major streets. These institutional buildings have vacant land parcels for congregational use. Open spaces are being used for festivals, political rallies and serve as extended parking spaces during these occasions. Only the spaces which are being used frequently exist and unused spaces usually lost. Rome has witnessed the loss of urban open spaces due to the non-functionality of spaces. Loukaitou-Sideris (1996) described this kind of spaces as a crack in the city because they correspond to in-between spaces, residual, under-utilized and often deteriorating. Abandonment and deterioration fill vacant space with trash and human waste.

What is noteworthy about this town is the availability of resources to cope up with future demands and retaining character during expansion. The identity of citizens in old cities can be strengthened through the physical and visual reinforcement of valuable historical elements as well as the emphasis on using them in urban design and planning. However, due to the lack of such elements in new towns, the issue of identity is somehow problematic. Due to the absence of history, culture, and collective memory derived from space, new towns will remain deprived of identity for a long time. They will not experience the formation of identity elements such as collective memory unless they move toward becoming conventional cities. It is noteworthy that the population moving from other places to these new

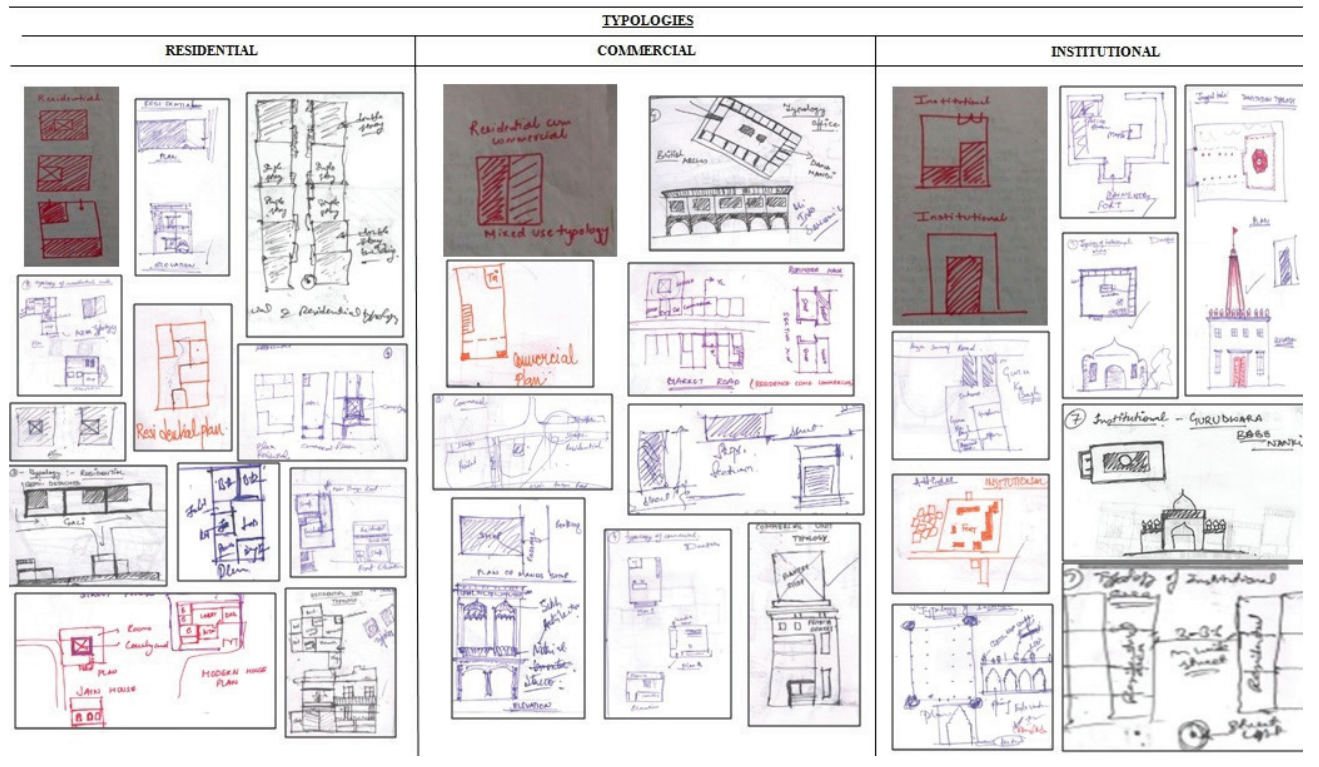

Figure 9. Landuse typologies (source: by author) 


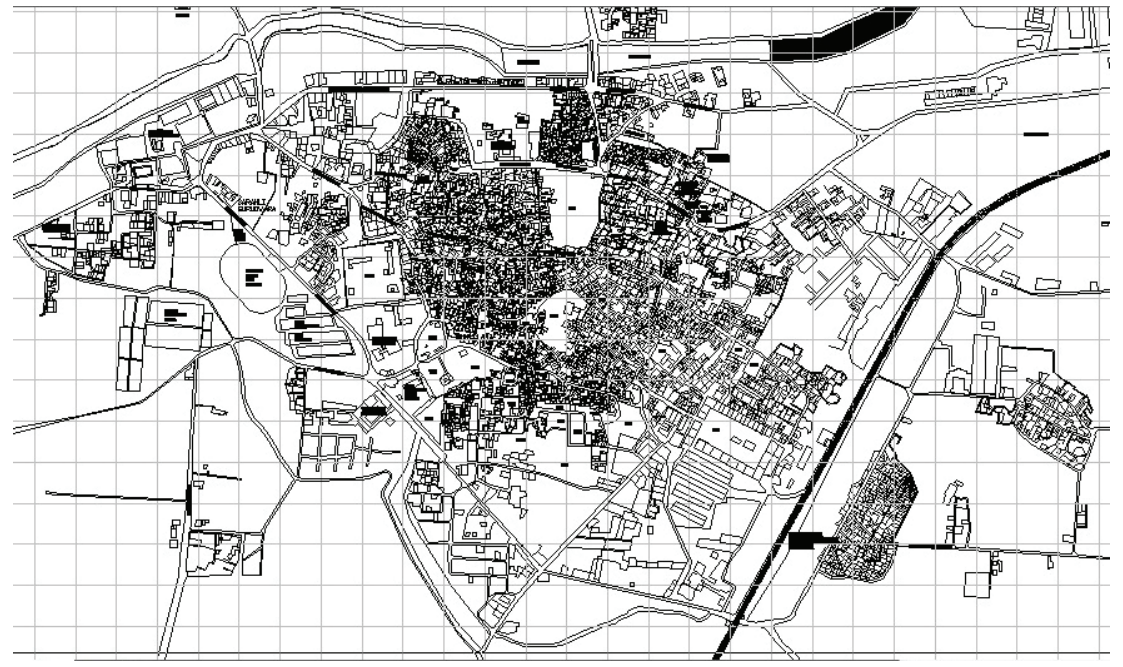

Figure 10. Base map Sultanpur Lodhi (source: by author)

towns has its own history, culture, and collective memory that can facilitate the process of identification, provided that they are considered conscious urban inhabitants.

Base map of city showing open and built up areas with clear demarcation of circulation. Density at city centre can easily be traced here. Circulatory roads are enabling future extensions.

\section{Historic city and contemporary urban design}

The dialogue may not explore the differences between urban designs of historical and new cities. It try to explore the identifiable urban design character and subsequent reviving mechanism in Sultanpur Lodhi. A long time back key factors of city formation are derived from commerce activities profound at Sultanpur Lodhi. How the contemporary urban design approach interacts with this historical city module can be summarized on the basis of principles, which are, conducive to social interactions, attractive to users, complement the area in context, permeable, legible, low-impact, the variety of uses and attract a variety of users, robust and responsive to physical, social, economic and political changes in the urban fabric. These principles are:

- Places for People.

- Enrich the Existing.

- Connect to the Surrounding Urban Fabric.

- Work the Landscape.

- Mixed Use.

- Design for Change.

\subsection{Places for people}

Successful urban spaces allow social interactions. Vacant land parcel on the axis joining two prominent Gurudwaras have provision for vibrant open space use (Figure 7). SGPC (Shiromani Gurudwara Prabhandak Committee, India) owned land is used for political rallies, ritual gatherings and also for alternative parking spaces
(Arshi, 1986). Interconnected road layouts have provision for pedestrian and vehicular traffic. In response to street widths and organic approach to planning vehicular traffic is restricted to inner pedestrian streets. Linear axis brings safety during mass gatherings (Figure 4). Findings here reveal the comment on New Urbanism given by Professor Vincent Scully (Paul, 2001), an architectural historian at Yale University "It's important that people are within walking distance of the center of town. Those streets are narrow and connected. And that a street is a place for people - not just automobile. We started thinking about architecture as the structure of human habitation."
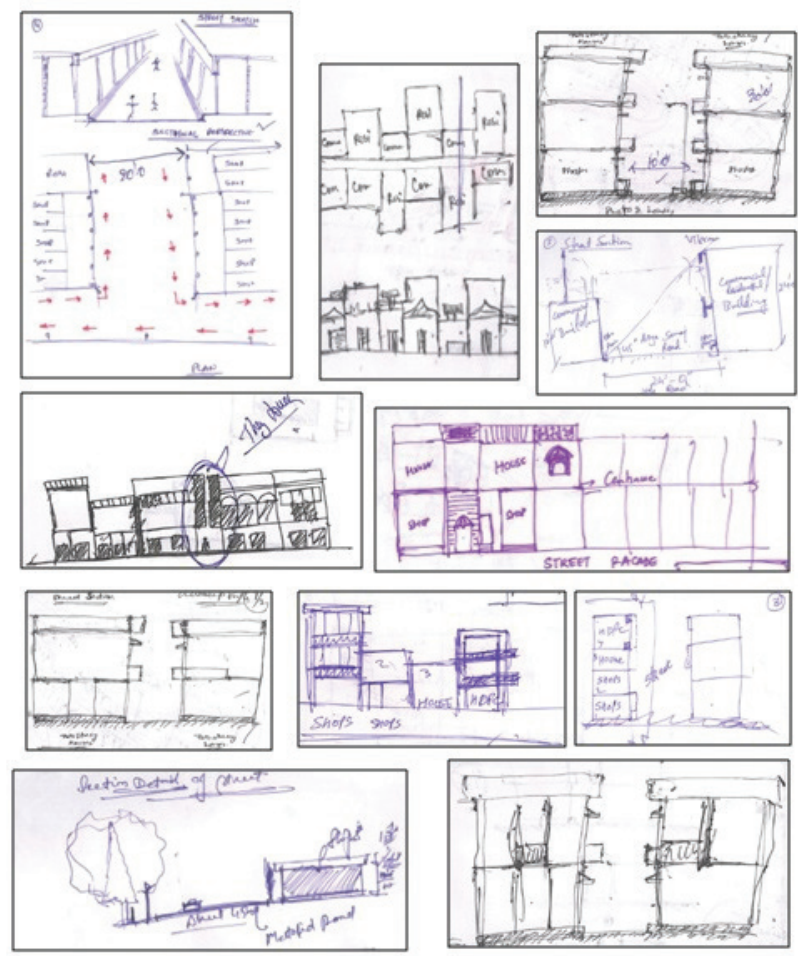

Figure 11. Street section and facades detail (source: by author) 
Buildings have street oriented balconies promote interaction during street activities. Friedrich Ragette (2003, p. 53) while discussing the dwellings in Arab region highlights their needs for seclusion of private areas for their women, however he noticed "as much as the seclusion of dwelling is desired, curiosity to see and hear what is going on in the generates the use of bay windows on the first floor (musharabiya)" (Figure 5). The concept of territory which so develops, thus, is more communal than personalized and this leads to the development of shared spaces. It is emphatic to assert here that the strong cultural bond of the community led to the formation of streets which bore an intimate character and these in turn, protected and fostered the culture of the communities at that time (Alexander, 1977). Shaded spaces of numerous old trees and double storied buildings at surroundings are vital for life. Monotonous effects of urban areas are being neutralized by adoption of various architectural styles.

\subsection{Enrich the existing}

The spaces are retaining each other strength and minimizing their weaknesses. New development is expanding in three directions from the existing city. New development depends on existing infrastructure in terms of facility, services, and identity. Market stretch which is famous for handicraft and local trade bisects the city layout diagonally. Apart from concentrated residential urban areas, commercial patches are visible throughout town (Figure 3). A mutual relationship of zoning can be identified over there. Sultanpur Lodhi declared as protected monument under the "The Punjab Ancient and Historical Monuments and Archaeological Sites and Remains Act, 1964".

Cultural map of city is showing location of cultural centers within city. A visual relationship of spacing, which responds to the cultural dimensions of historical city, is identifiable.

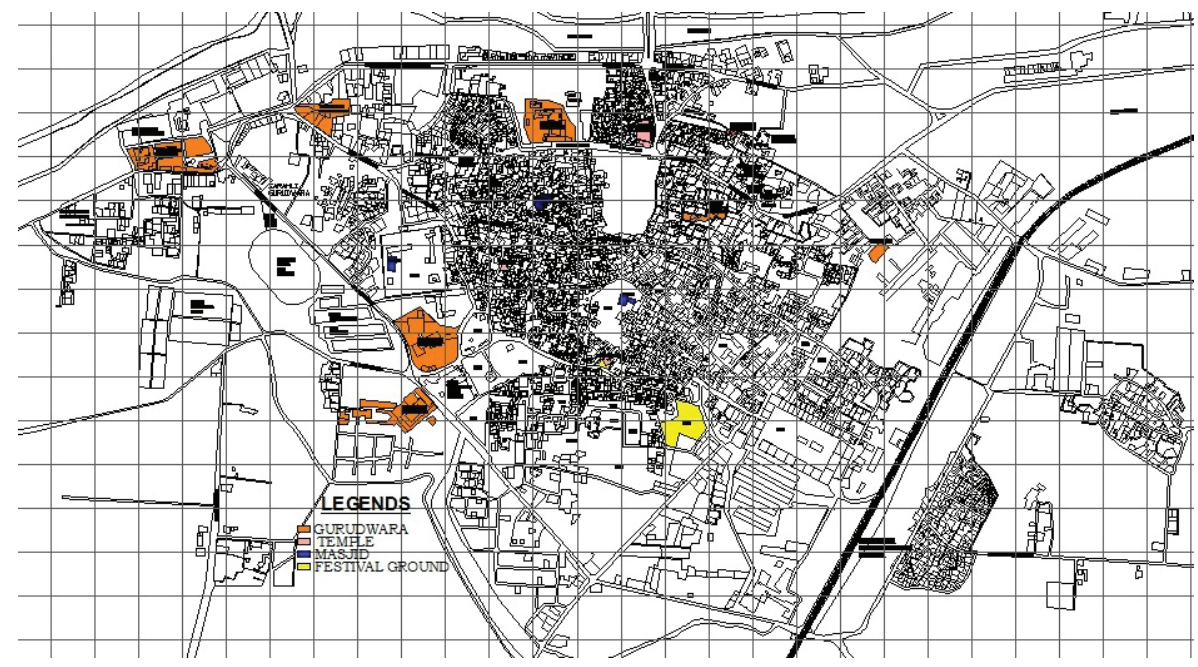

Figure 12. Cultural map Sultanpur Lodhi (source: by author)

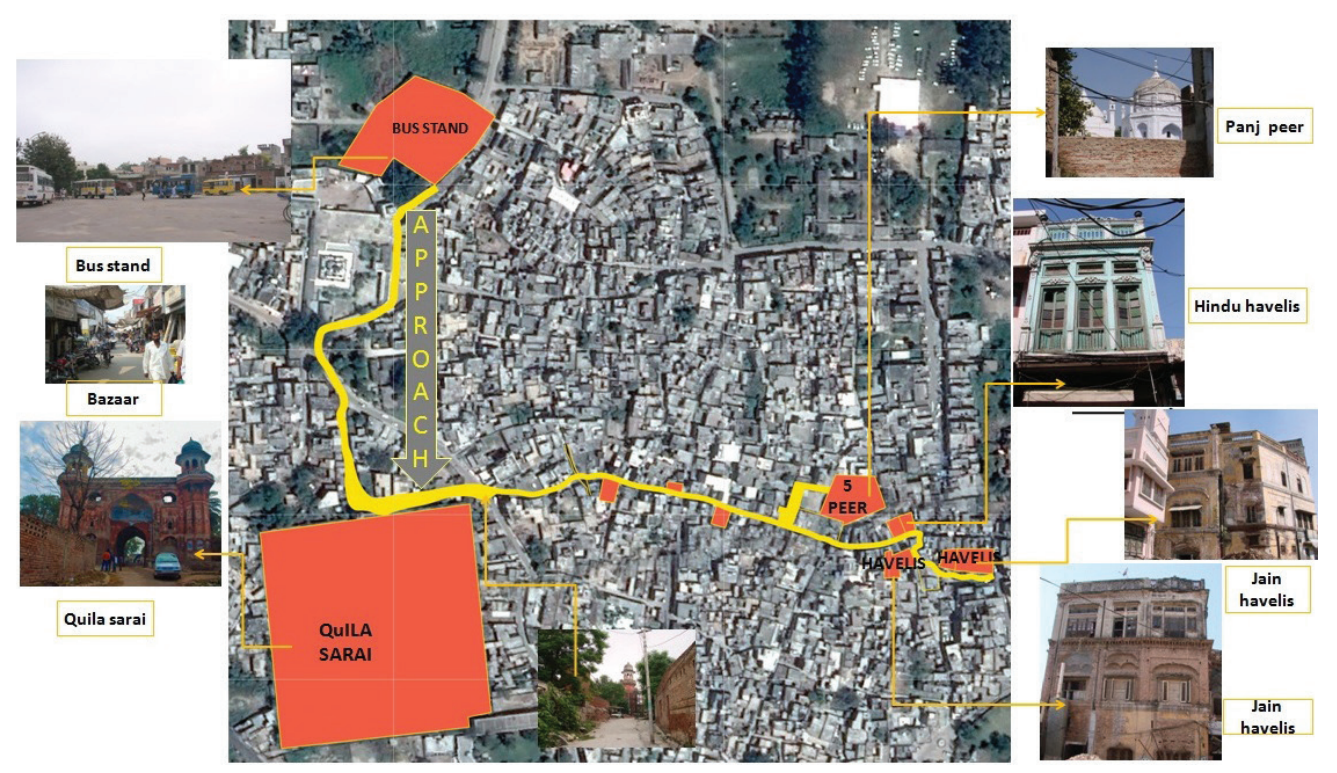

Figure 13. Proposed heritage walk at Sultanpur Lodhi (source: by author) 
This act ensures the Preservation of Ancient and Historical Monuments and Archeological Sites and Remains other than those of national importance, for the regulations of Archeological excavation and for the protection of sculpture carvings and other like objects, which are in existence for not less than 100 years (Office of archaeological survey of India, 2017).

Development and promotion of theme based heritage walk with local community participation can be a good option to enhance the tourist experience and increase economy generation. A special feature of Sultanpur Lodhi is the plan of the old city, traversed by narrow street patterns and usually terminating in squares. To experience the glory of Sultanpur Lodhi, it is necessary to walk through an old quarter and truly observe the nature of its architecture, its art, religious places, its culture and tradition. This proposed heritage walk consists the forts, marketplaces and historical imprints of numerous architectural styles may contribute to attracting global tourists and business opportunities thereof. Study regarding an identification of such buildings in the town has been conducted but sufficient record regarding this subject could not be found. However, one site named Hadira on Talwandi Chaudrian road and Quila located on Lohian road is found to be more than 100 years old and has a historical significance as the history of the town is related to these. Heritage walk proposal to this city may not only protect and promote the culture but brings business to city dwellers.

Attitudes, beliefs, values, customs, dress, decoration, symbols and codes of a particular community refer to the culture at wide. However, what is important here is the commonality which produces the identity over a course of time. Expressed as an important essence of life, the Punjab cultural identity has major overtones of religion and nature (Singh, 2004). Thus it is not only the religious buildings but also the residential areas which display the basic religious belief of worship, serenity and love for nature.
N. G. Jive' and P. J. Larkham (2003) emphasize upon the continuation of traditions as a link; 'the past exists as both individual and collective construct, with shared values and experiences being important within cultural groups. Group identity is thus closely linked with the form and history of the place, creating a sense of place or genius loci'.

The medieval civilization laid emphasis upon the visual and artistic means of expression, be it the art of the churches or the villas in the west or the places, forts and havelis (mansions) of the east. S. K. Langer (1958) elevates the status of art and beauty "the enjoyment of beauty is a kind of escape from the urgencies of place and time". The streets of the Sultanpur Lodhi also exhibit this kind of rich and versatile fabric (Figure 11).

\subsection{Connect to the surrounding urban fabric}

Urban places are connected to surrounding transportation and traffic routes. The spaces function with the surrounding circulation routes. However, the site should not only be physically but visually accessible and connected from the surrounding context (McGlynn, Smith, Alcock, Murrain, \& Bentley, 2015). Core resident groups and occasional visitors can commute on foot for daily needs and essential public amenities. An avenue stretch was identified at the outer perimeter of concentric density zone which is promoting business at Sultanpur Lodhi. As people experience this avenue for ritual, political, societal and trade purpose are invited to footwalks with beautiful landscape elements (Figure 13). It is always helpful to increase the sale of local handicrafts and trades which are associated with public interest. Walking phenomena result in more community involvement, public interaction and viable for public health in general (Gehl, 2011).

An interesting skyline may be traced here; commercial areas with varying building heights are stretching through a road amidst the city center. The seemingly unplanned,

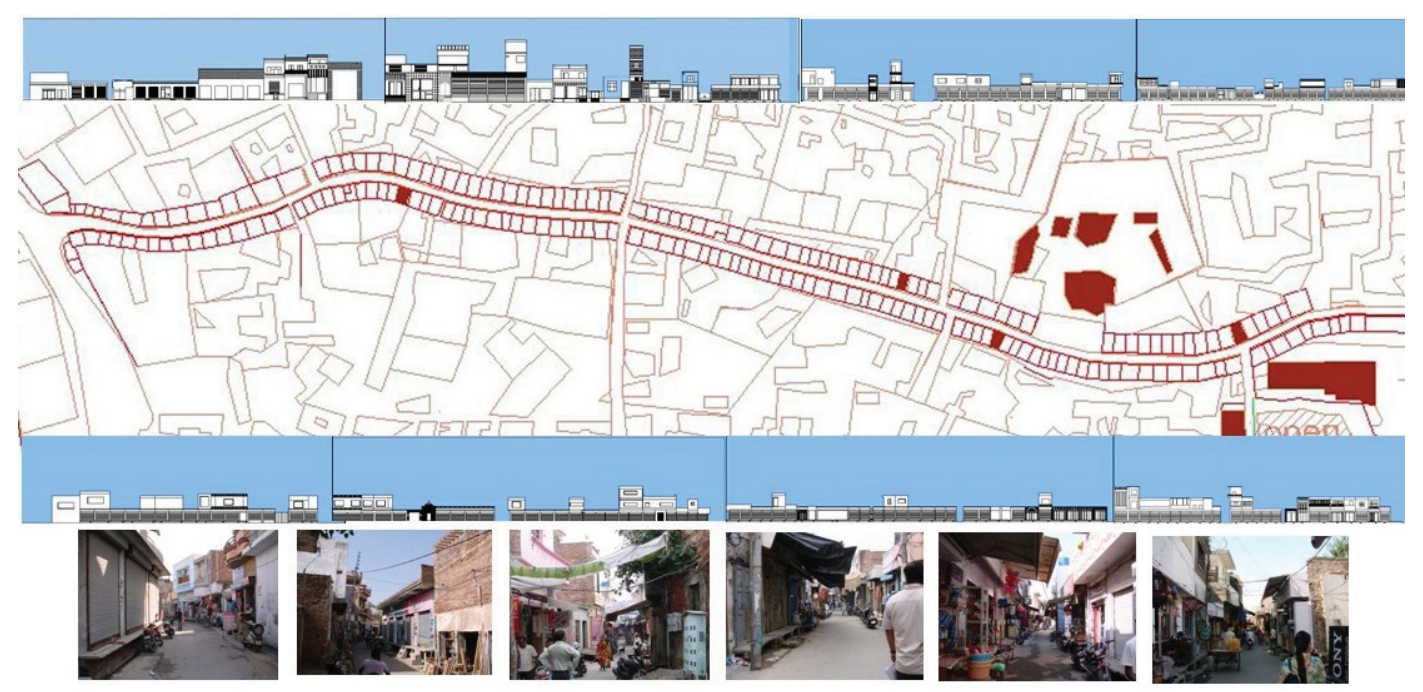

Figure 14. Map showing street view of commercial/residential stretch and corresponding building heights (source: by author) 
but extremely cohesive urban form of the city is a reflection of gradual development. The connecting roads are intersecting this road and providing an easy commute to nearby residents. As there is no existing service lane, segregation of vehicular and pedestrian traffic is questionable here. Over the past 15 years, the city has been transformed from concentrated and identifiable into an amorphous urban area. It encompasses destructions of built and natural elements and other hand eliminate the physical expression of indigenous ways of life that are very much part of this settlement. Whereas the more formal structure of planned cities like Chandigarh mirrors the controlled layout of streets and squares and the exposed elevations of public buildings.

\subsection{Work the landscape}

Urban spaces in the city, work with the landscape, form, ecology, microclimate and natural functions. This is promoting the landscape character of the area and minimizing the energy input and the level of disturbance to the site. Rivulet flows along Sultanpur Lodhi town named Kali Bein holds a very sacred part of Sikh religion. The $160-\mathrm{km}$-long rivulet starts from the land around Dhanao village in the Hoshiarpur district of Punjab. The minerals that seep into the river have lent the river its name as they cause the river to give a black reflection in the viewers' eye.

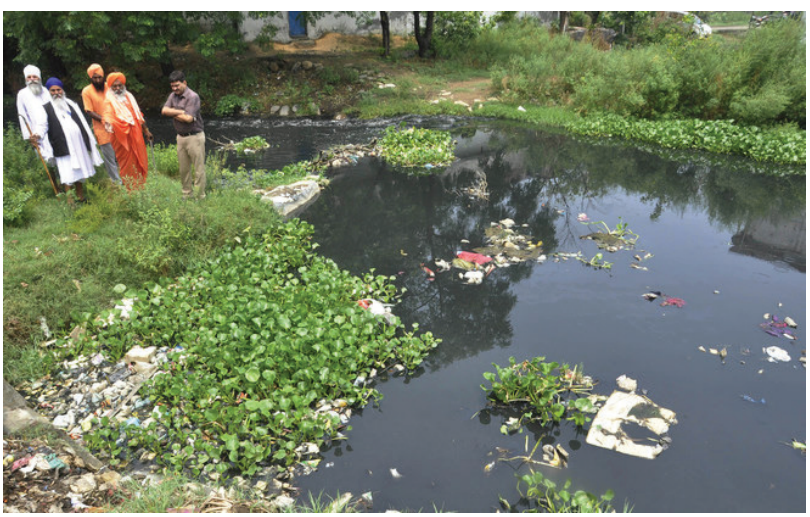

Figure 15. Rivulet condition in 2000 (source: Google image)
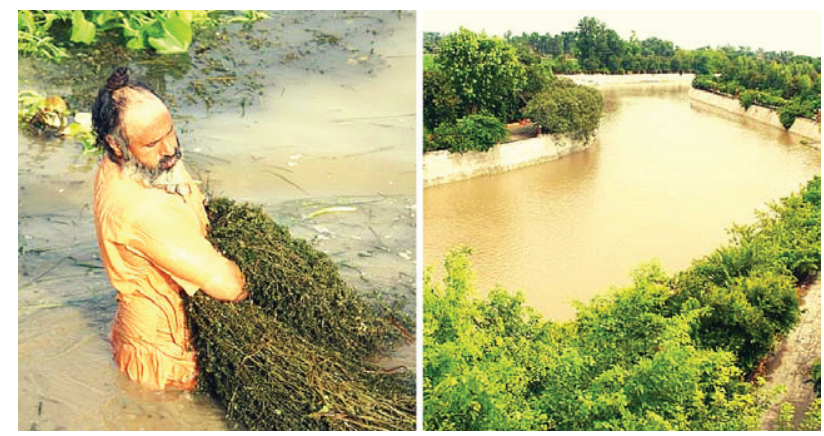

Figure 16. Rivulet water treatments 2000-2006 (source: Google image)
Rivulet named Kali Ben was polluted before conservation initiative taken by local people. Garbage was main reason of pollution and limited variety of aquatic plants was incapable to control (Figure 15). This rivulet nurtured the ecology, climate and contribute towards sustainable means to Sultanpur Lodhi. An initiative taken under public private partnership activity in 2000 by Sant Balbir Singh Seechewal has awakened the society and gave an idea to revive the urban character of existing town.

Water treatment of rivulet was proposed by a saint Sant Seechwal with pubic partnership. Water front; new species of plants (aquatic and flowering) and garbage prevention techniques were introduced (Figure 16).

Sensitivity towards natural resources as found in this city is vital to figure out the character of existing landscape (Hoyer, Dickhaut, Kronawitter, \& Weber, 2011). Developed river front contributing to the health-conscious life style, aesthetic purpose and diminishing fertile soil erosion due to rain and flood (Figure 17).

After renewal of river banks an adaptive landscape is prevailing as road stretches and visible soft landscape. This was major revival resource to trace contemporary approach within urban paradigm.

\subsection{Mixed use}

The variety of forms used, and activities in the city are attracting a large diversity of users from various ethnic groups, social classes and age groups. It enhances the use of the open space. The co-existence of residential with commercial and residential with industrial activities is the character of this city. This character is more prevalent in the inner zone of the city (Figure 14). This character "Mixed Land use" has developed over a period of time necessitated by the socio-economic habits of the people. This juxtaposed character of land uses have compact built form, narrow street circulation and low rise-high density development accommodating a mixture of land use in a single building. This brings cost saving in the provision of parking areas due to sharing of spaces during day and

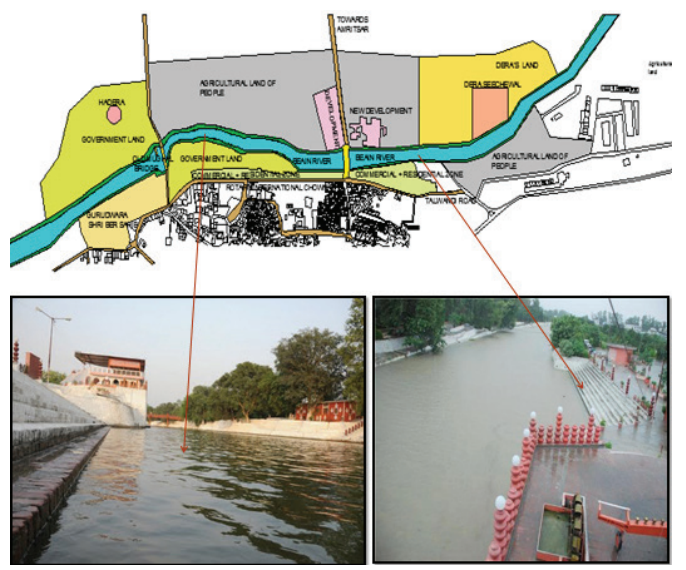

Figure 17. Rivulet condition after treatment (source: by author) 
night and it decreases the need for additional parking lots as residential and commercial zones are in close proximity to each other. Urban places as open grounds are sustainable, economically viable and maintained to continue success and function of the space. These spaces are frequently used for political rallies, ritual gatherings, and festivals and for Sports Activities. Municipal Corporation has maintained the city decorum in terms of water supply, sewerage facilities, and other public amenities.

\subsection{Design for change}

Identified Urban spaces are responsive to changes in the urban fabric and be used. This flexibility is needed to create multipurpose spaces.

Built open map of Sultanpur Lodhi showing potential of city growth by tracing open spaces.

Changes in design refer to potential withstand for changes in population growth, related infrastructure, climatic variations etc. These changes bring variations in built environment, transportation system and subsequently energy demands for growing needs. Spaces within the city are partially enclosed and static in functionality while at city boundary these are organic in nature and oriented to flexible future extensions (Figure 10). Though the city is situated on the southern bank of the rivulet, the growth can be traced in a radial pattern based on originating web arteries of the road network (Figure 18).

An assessment of cities natural resources brings the idea to Riverfront development at Sultanpur Lodhi. It may contribute to a sustainable approach towards urban heritage, economic development, functionality and livability of the city. A Proposal to develop Riverfront meets the goal of tourism promotion, preservation of plant species and the availability of recreational areas for city dwellers (Figure 19). The river "Kali Ben" is the vein of the city and it could be developed in collaboration with public-private partnership by development authorities. Integration of urban heritage values contributes to a wider framework of city development. Within the waterfront development,

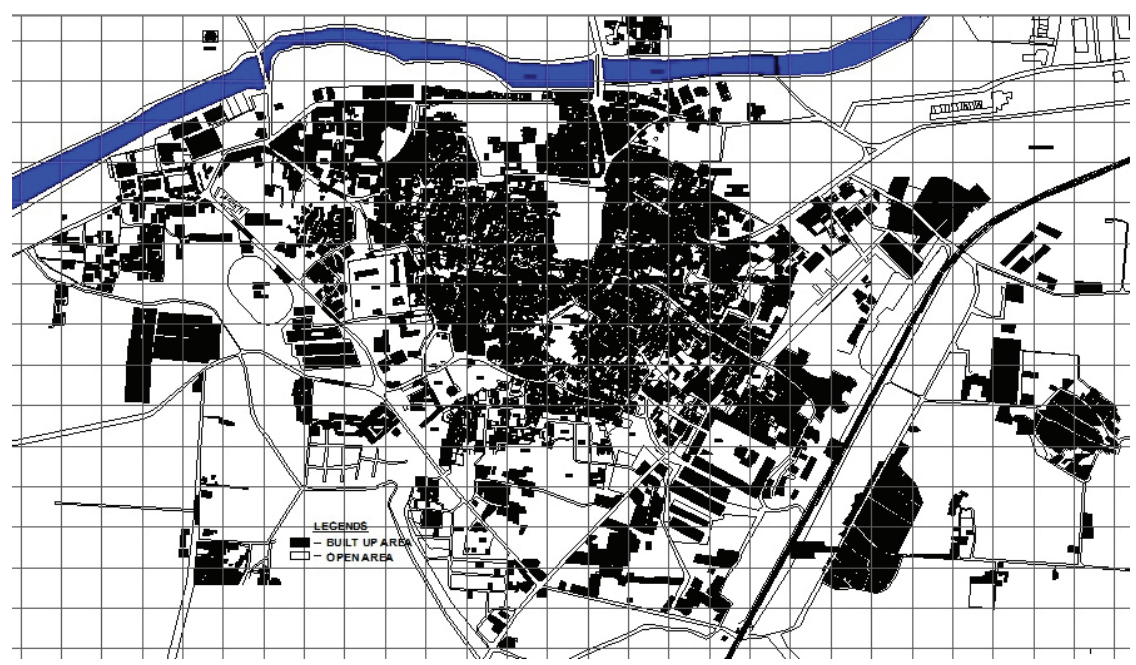

Figure 18. Built open Sultanpur Lodhi (source: by author)

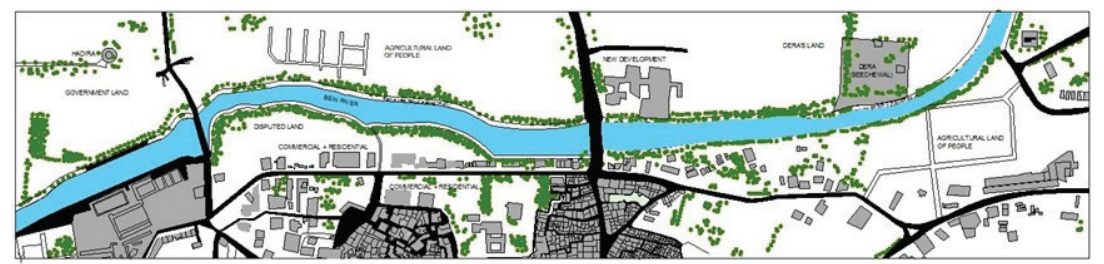

Existing Land Use Plan Along with River

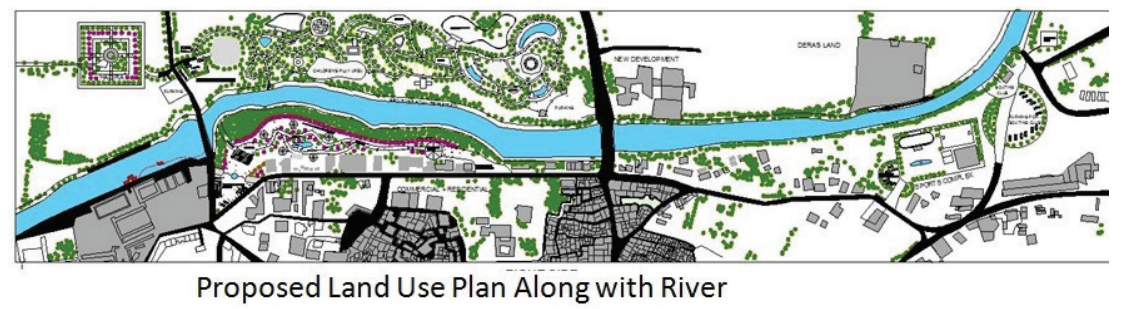

Figure 19. Proposed Riverfront development (source: by author) 
the semi-open and open places like amphitheatre can be designed for enhanced public use. Redesigning the streetscape and strengthening of public infrastructure around the main approaches to historic precincts, especially proposed heritage walk (Figure 13) and along with river Kali Ben should be undertaken to retain the historic character. The link between heritage structure, site development and its economic implications are always critical for the success of revitalization projects. Strategies and framework should be envisioned to ensure that urban revitalization must result in enhanced income opportunities and improved quality of life for local communities.

\section{Conclusions}

The design of a new city is easy as compared to the revival of existing one. The Belief, habits, trade and overall culture of people demand stability or consistency in living while the skeleton of new design theories has a spine of collective modules. These are blocks, clusters, roads, and related infrastructure which are likely to be adopted for growing population needs. Urban designers criticized that Urban Design guidelines restrict their creativities. But there is enough evidence in the Sultanpur Lodhi unity within individual interpretation from various periods is welcomed in the essence of urbanism. The city is an organism and if it cannot adapt to the changes in its layers, it loses its being. Since its life and soul lay in its people, the city needs to keep updating itself with the growing aspirations and root culture.

Waterfront development shall be extended to set up a museum to showcase the Buddhist, Mughal and Sikh heritage, costumes, utensils and artifacts for the visitors. Renovation of traditional residences and adaptive re-use of residences to apartments with modern facilities needs to be encouraged maintaining the character and culture. The economic balance of the settlement through alternate income generation in terms of heritage tourism needs to be explored and developed (Ercoskun, 2011). Along with the recommendations provided in this paper, further exploration may be carried out for the improvement of urban design elements and community-based area renewal schemes in the area. Study of Urban Design at Sultanpur Lodhi demonstrate that the revival of existing cities is subjected to the close study of external conflicts, their footprints on habitats, gradual changes due to growth, resources potential within the city and the geographical correlation with nearby cities. The findings and observations from the study highlight the fact that, although presently the historic urban quarter in the city is under severe stress, there are enormous opportunities for renewing such area through enhanced tourism economy. The range of newly developed cities and marked peripheries of old cities are witnessing the densification without considering the ecology of the region. Such practices result in the exploitation of existing resources and can't be justified.

\section{Acknowledgements}

The author duly acknowledges the contribution of the final year students (Batch, 2015) of Master Programme in Architecture at CoA, IET Bhaddal to provide base drawings, and the two unknown referees for insightful and productive comments on the draft manuscript.

\section{References}

Alexander, C. (1977). A pattern language: towns, buildings, construction. Oxford: University Press.

Ali, M. M. (2015). An overview on Madarsa education in India. International Journal of Development Research, 5(03), 37143716.

Arshi, P. S. (1986). Sikh architecture in Punjab. India: East India Book Co.

Ercoskun, O. Y. (2011). Green and ecological technologies for urban planning: creating smart cities (1st ed.). Hershey, Pennsylvania: IGI Global.

Gehl, J. (2011). Life between buildings (2nd ed.). London: Island Press.

Hayden, D. (1995). The power of place: urban landscapes as public history. Cambridge: The MIT Press.

Hoyer, J., Dickhaut, W., Kronawitter, L., \& Weber, B. (2011). Water sensitive urban design: principles and inspiration for sustainable stormwater management in the city of the future. Switzerland: Distributed Art Pub Inc.

Jive'N. G., \& Larkham, P. J. (2003). Sense of place, authenticity and character: a commentary. Journal of Urban Design, 8(1), 6781. https://doi.org/10.1080/1357480032000064773

Loukaitou-Sideris, A. (1996). Cracks in the city: Addressing the constraints and potentials of urban design. Journal of Urban Design, 1, 91-103. https://doi.org/10.1080/13574809608724372

Lynch, K. (1960). The image of the city. Cambridge: The MIT Press.

McGlynn, S., Smith, G., Alcock, A., Murrain, A., \& Bentley, I. (2015). Responsive environments (1st ed.). Elsevier Linacre House, Jordan Hill, Oxford, United Kingdom: Routledge.

Office of archaeological survey of India. (2017, March 05). Retrieved from https:// asi.nic.in/

Office of Punjab urban planning and development authority. (2017, September 11). Retrieved from https://www.puda.gov.in/

Paul, N. C. (2001). Interview with Vincent Scully. In Putting people back into architecture. The Christian Science Monitor.

Ragette, F. (2003). Traditional domestic architecture of the Arab region. Germany, Great Britain: Edition Axel Menges.

Singh, D. (2004). The Sikh heritage: a search for totality. New Delhi: Prakash Book Depot.

Tersteeg, A. K., \& Albeda, Y. (2015). Urban diversity as a "stayfactor"? Neighbourhood choice and satisfaction in hyper-diverse contexts. In International Conference on "The ideal city: between myth and reality. Representations, policies, contradictions and challenges for tomorrow's urban life" Urbino. Italy. 